\title{
Oncometabolites and the response to radiotherapy
}

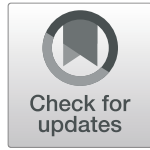

Kexu Xiang, Verena Jendrossek and Johann Matschke* (D)

\begin{abstract}
Radiotherapy (RT) is applied in 45-60\% of all cancer patients either alone or in multimodal therapy concepts comprising surgery, RT and chemotherapy. However, despite technical innovations approximately only $50 \%$ are cured, highlight a high medical need for innovation in RT practice. RT is a multidisciplinary treatment involving medicine and physics, but has always been successful in integrating emerging novel concepts from cancer and radiation biology for improving therapy outcome. Currently, substantial improvements are expected from integration of precision medicine approaches into RT concepts.

Altered metabolism is an important feature of cancer cells and a driving force for malignant progression. Proper metabolic processes are essential to maintain and drive all energy-demanding cellular processes, e.g. repair of DNA double-strand breaks (DSBs). Consequently, metabolic bottlenecks might allow therapeutic intervention in cancer patients.

Increasing evidence now indicates that oncogenic activation of metabolic enzymes, oncogenic activities of mutated metabolic enzymes, or adverse conditions in the tumor microenvironment can result in abnormal production of metabolites promoting cancer progression, e.g. 2-hyroxyglutarate (2-HG), succinate and fumarate, respectively. Interestingly, these so-called "oncometabolites" not only modulate cell signaling but also impact the response of cancer cells to chemotherapy and RT, presumably by epigenetic modulation of DNA repair.

Here we aimed to introduce the biological basis of oncometabolite production and of their actions on epigenetic regulation of DNA repair. Furthermore, the review will highlight innovative therapeutic opportunities arising from the interaction of oncometabolites with DNA repair regulation for specifically enhancing the therapeutic effects of genotoxic treatments including RT in cancer patients.
\end{abstract}

Keywords: Oncometabolites, lonizing radiation, DNA repair, Epigenetic regulation

\section{Background}

Radiotherapy (RT) is commonly used to treat cancer, especially solid tumors. RT uses the local application of ionizing radiation (IR) to target and to kill cancer cells with high precision and has beneficial effects on locoregional control, overall survival and cure rates in various tumor types. In fact, the therapeutic potential of RT alone and in multimodal combinations with surgery, chemotherapy, and targeted drug therapy has increased

\footnotetext{
* Correspondence: Johann.Matschke@uk-essen.de

Institute of Cell Biology (Cancer Research), University Hospital Essen,

University of Duisburg-Essen, Virchowstrasse 173, 45147 Essen, Germany
}

considerably during the past decades [1]. However, advanced cancers are characterized by pronounced radioresistance, leading to local relapse, whereas coirradiation of normal tissues may lead to toxicity, thereby limiting the maximal applicable RT dose. The risk of adverse effects also limits therapy intensification efforts by combining RT with any other cancer therapy, RT dose escalation, so that local recurrence of primary tumors and distant metastases remain leading causes of death in many cancer patients $[2,3]$.

The broad use of RT as standard treatment option in the therapy of solid human tumors is based on its ability

(c) The Author(s). 2020, corrected publication 2020. Open Access This article is licensed under a Creative Commons Attribution 4.0 International License, which permits use, sharing, adaptation, distribution and reproduction in any medium or format, as long as you give appropriate credit to the original author(s) and the source, provide a link to the Creative Commons licence, and indicate if changes were made. The images or other third party material in this article are included in the article's Creative Commons licence, unless indicated otherwise in a credit line to the material. If material is not included in the article's Creative Commons licence and your intended use is not permitted by statutory regulation or exceeds the permitted use, you will need to obtain permission directly from the copyright holder. To view a copy of this licence, visit http://creativecommons.org/ licenses/by/4.0/. The Creative Commons Public Domain Dedication waiver (http://creativecommons.org/publicdomain/zero/1. 0/) applies to the data made available in this article, unless otherwise stated in a credit line to the data. 
to damage cellular macromolecules, particularly DNA double strand breaks (DSB) thereby effectively inducing growth arrest, and cell death in irradiated tumor cells [4]. However, high intrinsic, microenvironmentmediated, and adaptive radioresistance of solid human tumors, remain major obstacles to successful RT. For example, the cytotoxic efficacy of radiotherapy relies on the local availability of molecular oxygen $\left(\mathrm{O}_{2}\right)$ in the tumor tissue during treatment delivery for the generation of reactive oxygen species (ROS) and the fixation of RT-induced DNA damage. Consequently, an acute severe decrease in $\mathrm{O}_{2}$ levels ("tumor hypoxia") by insufficient $\mathrm{O}_{2}$ supply, increased $\mathrm{O}_{2}$ demand, or both, confers direct resistance by decreasing oxidative stress and therapy-induced cell killing [5].

Important molecular determinants of intrinsic and acquired radioresistance are i) the cellular capacity to detoxify radiation-induced $\mathrm{ROS}$ and ii) the capacity to perform efficient repair of RT-induced DNA damage, particularly the most lethal DSBs [6]. Although DSBs stand for small proportion of DNA lesions induced by RT [7], they are an enormous challenge. Therefore, cells developed various mechanisms to ensure survival amongst others by distinct pathways for DSB repair, e.g. non-homologous end-joining (NHEJ), homologous recombination repair (HRR), or alternative end-joining (alt-EJ) $[8,9]$. Consequently, genetic abnormalities that enhance the capacity of cancer cells to perform DSB repair via NHEJ, HRR, or alt-EJ promote cancer cell survival exposed to genotoxic therapies and enhance radioresistance [10-12]. Instead, genetic abnormalities leading to defects in the DNA damage response (DDR) and DNA DSB repair pathways such as early onset Breast cancer 1/2 (BRCA1/2) enhance sensitivity to DNA-damaging treatments, such as chemotherapy and radiotherapy, and generate specific vulnerabilities to inhibitors of complementary DSB repair pathways in socalled synthetic lethality approaches [13-17].

Interestingly, emerging evidence indicates that factors beyond genetic defects in core proteins of DDR and DSB repair, e.g. microenvironmental cues $[5,18-20]$ or deregulated expression or mutations in chromatin modifiers [21-24] or metabolic enzymes [10, 25] can also promote DSB repair defects in cancer cells with important therapeutic implications. Moreover, the ability of cancer cells to maintain cellular redox homeostasis and high antioxidant capacity as part of the metabolic reprogramming during malignant progression has relevance to radioresistance [10, 25-29]. Finally, metabolic adaptation of cancer cells to adverse conditions in the tumor microenvironment or treatment-induced stress can promote acquired radioresistance offering additional targets for tumor-specific radiosensitization [10, 25, 29-33]. However, one caveat of using metabolic inhibitors in cancer therapy remains the large molecular heterogeneity within and between different tumors, highlighting the urgency to develop reliable biomarkers for patient stratification.

Taken together, there is a high medical need for novel and effective biology-based strategies for a tumorspecific radiosensitization. Research in molecular radiobiology and radiation oncology therefore aims to define genetic and environmental factors that mediate intrinsic and adaptive radiation resistance in individual tumors, as well as cancer cell specific defects that may allow for a tumor-specific radiosensitization on an individual basis, including heterogeneous tumors.

\section{Main text}

Role of genetic and epigenetic alterations of DSB repair for radioresistance

NHEJ and HRR are considered as the two major DSB repair pathways [8]. The cell cycle-independent NHEJ is a very fast but error prone DSB repair machinery, whereas HRR is only active if the template DNA for repair is present (G2/S cell cycle phase) [9]. Both pathways rely on a certain set of proteins Therefore, it is not surprising that documented genetic alterations in gene expression or signaling of these DSB repair proteins influences efficiency of DSB repair and thus the sensitivity of cancer cells to RT [22, 23, 34-37]. However, DNA repair is also regulated by epigenetic enzymes, both on the chromatin and the DNA level $[24,38-44]$ : The molecular details of the interplay between epigenetics and DSB repair has been described by others and will therefore not be described in detail here (for details see reviews by Dabin J et al. [43], Lahtz C et al. [42] and Gong F et al. [43].).

\section{Therapeutic strategies using synthetic lethality with genetic defects in DSB repair}

With the advent of the genomics era evidence is now accumulating that cancer cells are characterized by pronounced genomic instability and also more frequently harbor defects in DNA repair proteins than expected, including core proteins of DSB repair [5, 16, 45]. Interestingly, such cancer-cell specific alterations in a core DSB repair protein enhance vulnerability to drugs interfering with the respective alternative DSB repair pathways, and this effect can be further enhanced when such drugs are combined with DNA damage-inducing treatments, e.g. RT or genotoxic chemotherapy [16, 45-47]. The underlying concept of synthetic lethality had been developed for tumors with loss-of function mutations in HR-genes BRCA1 or BRCA2 [45, 47]. BRCA-mutant tumors harbor defects in HR-repair ("BRCAness" or "HRness") and this is synthetically lethal with inhibition of Poly(ADPRibose)-Polymerase (PARP)-dependent DNA repair pathways using PARP-inhibitors [45-47]. However, 
cancer cells can also develop resistance against treatments with DNA repair inhibitors highlighting the need for novel therapeutic approaches to prevent or overcome resistance and for the identification and validation of robust biomarkers predicting response or resistance to inhibitors of the DNA damage response and DNA repair $[46,48]$. In this context, intrinsic or pharmacologically induced metabolic defects in HRR may offer elegant opportunities for improving the outcome of cancer therapy beyond synthetic lethality approaches with PARPi, e.g. by using inhibitors of NHEJ (e.g. inhibitors of DNAdependent serine/threonine protein kinase (DNA-PK)). As outlined above, oncogene-induced or drug-induced metabolic constraints of HRR will also enhance radiosensitivity of cancer cells. Here, the suggested higher relative importance of HRR for the repair of DNA damage induced by particle therapy (e.g. carbon ions [49], and proton beam therapy [50-53]) may even offer potential future opportunities for the stratification of patients with oncometabolite-rich tumors towards particle therapy, or combining particle therapy approaches with metabolic drugs inducing HRR defects during therapy.

In this context, a concept of metabolic induction of DNA repair defects could represent an elegant opportunity for improving the outcome of RT allowing for a cancer-cell specific radiosensitization of cancer cells with genetic defects or pharmacologic inhibition of endjoining (EJ) dependent pathways and even synergize with potential differences in the biology of DNA damage induced by irradiation with proton beams compared to irradiation with gamma-ray photons or X-ray photons.

\section{Genetic defects in cancer cells and accumulation of oncometabolites}

Various studies demonstrate that nuclear and mitochondrial DNA-encoded mitochondrial genes are mutated in cancer and that this phenomenon is connected with poor clinical outcome and prognosis $[54,55]$. However, not all cancers exhibit mitochondrial dysfunction and it should be emphasized that the complete loss of mitochondrial function is detrimental for cancer cells [56]. Identification of cancer-associated mutations in genes with impact on the cellular metabolism has drawn great attention during recent years [57-62]: Some of these mutations introduce abnormal production of certain metabolites with relevance to cancer progression, termed "oncometabolites". Researchers have unveiled the abnormal production of 2-hydroxyglutarate (2-HG), succinate and fumarate in cancer and linked their critical roles to cellular metabolic transformation and biological processes [63-66]. Reprogramming of cancer cell metabolism, as a consequence of genetic and epigenetic alterations, can influence the metabolic phenotype of cancer cells and the production of oncometabolites, thereby enhancing downstream oncogenic cascades [67]. Furthermore, by altering anti-immune response and activating dormant and therapy-resistant cancer cells oncometabolites can also modulate tumor progression, cancer aggressiveness and tumor repopulation after radio- or chemotherapy [68-72].

\section{Succinate}

Succinate is a critical metabolite of the tricarboxylic acid cycle (TCA) and plays an important role in cellular metabolic processes [73]. Succinate dehydrogenase (SDH) is an enzyme complex composed of four subunits (SDHA, SDHB, SDHC, SDHD), and is also termed mitochondrial complex II of the mitochondrial electron transport chain (ETC) $[74,75]$. Defects in SDHB, SDHC, SDHD, but not SDHA, have been linked to disturbed function of complex II in the mitochondria [76] and impaired oxidation of succinate to fumarate. Furthermore, a loss-of-function mutation of SDH and the accompanied overproduction of succinate have been linked to the onset of cancer $[65,66]$ as well as to tumor repopulation after radio- or chemotherapy (as reviewed in [71]). However, the proper SDH function requires participation of oxidized $\mathrm{FAD}^{+}$and $\mathrm{NAD}^{+}$as cofactors, which are short of supply in cancer cells due to mitochondrial dysfunction [77]. Succinate accumulation facilitated angiogenesis by stimulation of succinate receptor 1 (SUCNR1) and accompanied up-regulation of vascular endothelial growth factor (VEGF) expression [78, 79]. Succinate accumulation also activated pathways connected to epithelial-to-mesenchymal transition (EMT), tumor migration, and invasion [80-83], and this might contribute to treatment-induced tumor repopulation and cancer relapse $[68,71]$.

As expected, SDH deficiency was linked to metabolic reprogramming in cancer cells, and promoted a glycolytic, pseudo-hypoxic phenotype. Genetic knockdown of SDHB in hepatocellular carcinoma (HCC) cell lines, resulted in decreased expression of Complex III and IV of the ETC and increased acidity of the cytoplasm suggesting a switch of cancer cells from mitochondrial respiration to glycolysis as main energy source, known as Warburg effect $[84,85]$. The occurrence of a pseudohypoxic phenotype induced by succinate accumulation highlights an additional role of this oncometabolite in the modulation of immune responses e.g. promoting the release of the pro-inflammatory chemokine IL-1- $\beta$ by innate immune cells, such as bone-marrow-derived macrophages (BMDMs) [86]. Interestingly, it has been demonstrated that RT-induced changes in miRNAexpression (miRNA-210, miRNA-31, miRNA-378) modulate the expression of SDH leading to succinate accumulation [71, 87-91]. Even more important, it has been proposed that miRNA-regulated succinate 
accumulation might promote tumor repopulation and cancer relapse [71].

\section{Fumarate}

Similar to succinate, fumarate is an important metabolite of the TCA cycle. Loss of function of fumarate hydratase (FH) was linked to overproduction of fumarate, and gave rise to hereditary leiomyomatosis and renal cell cancer (HLRCC) [65, 66]. High fumarate levels can adjust the balance of biochemical reactions in which this oncometabolite plays a role either as substrate or product. For instance, it was demonstrated, that fumarate accumulation impacts the conversion of succinate to fumarate in the TCA cycle, leading to disturbance of SDH-related mitochondrial respiration [92]. Fumarate-accumulation also gave rise to metabolic reprogramming towards argininosuccinate-accumulation via reversal of the urea cycle [93]. Notably, FH-mutated cells require a constant supply of exogenous arginine to keep the urea cycle active and are disabled when arginine is short-of-supply, thereby creating a cancer-specific vulnerability. Similarly, accumulation of fumarate promotes overproduction of adenylosuccinate by reversal of adenylosuccinate lyase (ADSL) within the purine nucleotide cycle (PNC) [93]. In contrast to succinate, fumarate also alters the posttranslational modification of cysteine residues of several proteins, called succination. Succination induced by FHdeficiency led to inhibition of mitochondrial respiration, activated antioxidant response, and tumor growth [92, 94-96]. Furthermore, FH-deficient cells reprogram their metabolism in the direction of aerobic glycolysis to provide energy [97]. Thereby, part of carbons from glucose are diverted toward the pentose phosphate pathway (PPP) to maintain redox homeostasis [96].

Furthermore, FH, like SDH, is also regulated by RTinduced miRNA-378 resulting in fumarate accumulation, and might thereby contribute to processes triggering tumor repopulation [71, 98].

\section{2-hydroxyglutarate (2-HG)}

Accumulation of the 2-HG enantiomers L2-HG or D2HG can occur under the following conditions: i) as pathologic metabolites in hypoxic cancer cells produced by lactate dehydrogenase (LDH) or malate dehydrogenase (MDH), respectively, [99-101]; or ii) as "oncometabolites" as a consequence of gain-of-function mutations in the genes coding for isocitrate dehydrogenase 1 or 2 (IDH1 or IDH2) [102, 103]. Herein, LDH and MDH seem to be the primary enzymes responsible for L2-HG generation in hypoxia [99-101], overproduction of D2HG has been linked to gain-of-function mutations in IDH $[101,102]$. Importantly, 2 HG was proposed as a potential biomarker for monitoring therapy-response in
IDH-mutant glioblastoma patients [104]. Moreover, accumulation of L2-HG has also been observed in renal cell carcinoma as well as in children with defects in ETC components, respectively [105-107]. Accumulating evidence further indicates that L2-HG mediates inhibition of the cellular differentiation process of mouse hematopoietic stem cells $[68,108]$. Additionally, 2-HG reprograms nuclear cancer stemness program by impairing histone demethylation thereby lowering the energy barriers separating non-stem and stem-cells [70, 109]. Furthermore, tumor-cell derived D2-HG is taken up by $\mathrm{T}$ cells and reprograms nuclear factor of activated $\mathrm{T}$ cells (NFAT) transcriptional activity and polyamine biosynthesis, resulting in suppression of $\mathrm{T}$ cell activity [72]. These findings highlight a sophisticated crosstalk between cancer cells and tumor-infiltrating immune cells where the oncometabolites modify or inhibit the function of tumor infiltrating immune cells and thereby favor cancer cell proliferation, tumor expansion, and metastasis formation $[72,110]$ with potential relevance to radiotherapy [69].

\section{Therapeutic perspectives}

Interestingly, the oncometabolites 2-HG, succinate and fumarate described above act as competitive inhibitors of $\alpha$ Ketoglutarate (KG)-dependent dioxygenases ( $\alpha$ KGDD) [111]. The family of $\alpha$ KGDDs use $\mathrm{O}_{2}$ and $\alpha K G$ as cofactors to perform a range of oxidation reactions e.g. modification of chromatin or regulation of protein stability, e.g. of hypoxia-inducible factors [112] (Fig. 1). Interestingly, various epigenetic enzymes belong to families of $\alpha$ KG-dependent enzymes, e.g. $\alpha$-KG-dependent histone lysine demethylase (KDM) and ten eleven translocation (TET) DNA demethylases with documented regulatory functions in DSB repair [16, 24, 39, 40,113, 114] of the above oncometabolites will impair DNA repair by inhibition of KDMs and TET DNA demethylases and the resulting histone/DNA hypermethylation [24, 115-118]. The oncometabolite-dependent regulation of $\alpha \mathrm{KG}$ dependent epigenetic enzymes with impact on DNA repair offers new and exciting avenues for a cancer cellspecific radiosensitization and improved radiotherapy outcome, as outlined in the following paragraphs.

\section{Succinate}

The above-mentioned succinate effects on regulation of EMT, metastasis, metabolic reprogramming and tumor repopulation are known as critical determinants of radiosensitivity $[71,119,120]$. SDH-deficient cells displayed competitive inhibition of several $\alpha$-KGDDs, due to progressive succinate accumulation [80]. In more detail, succinate accumulation competitively inhibits $\alpha$ KG-dependent dioxygenase, a ten eleven translocation (TET) enzyme, which is responsible for the oxidation of 


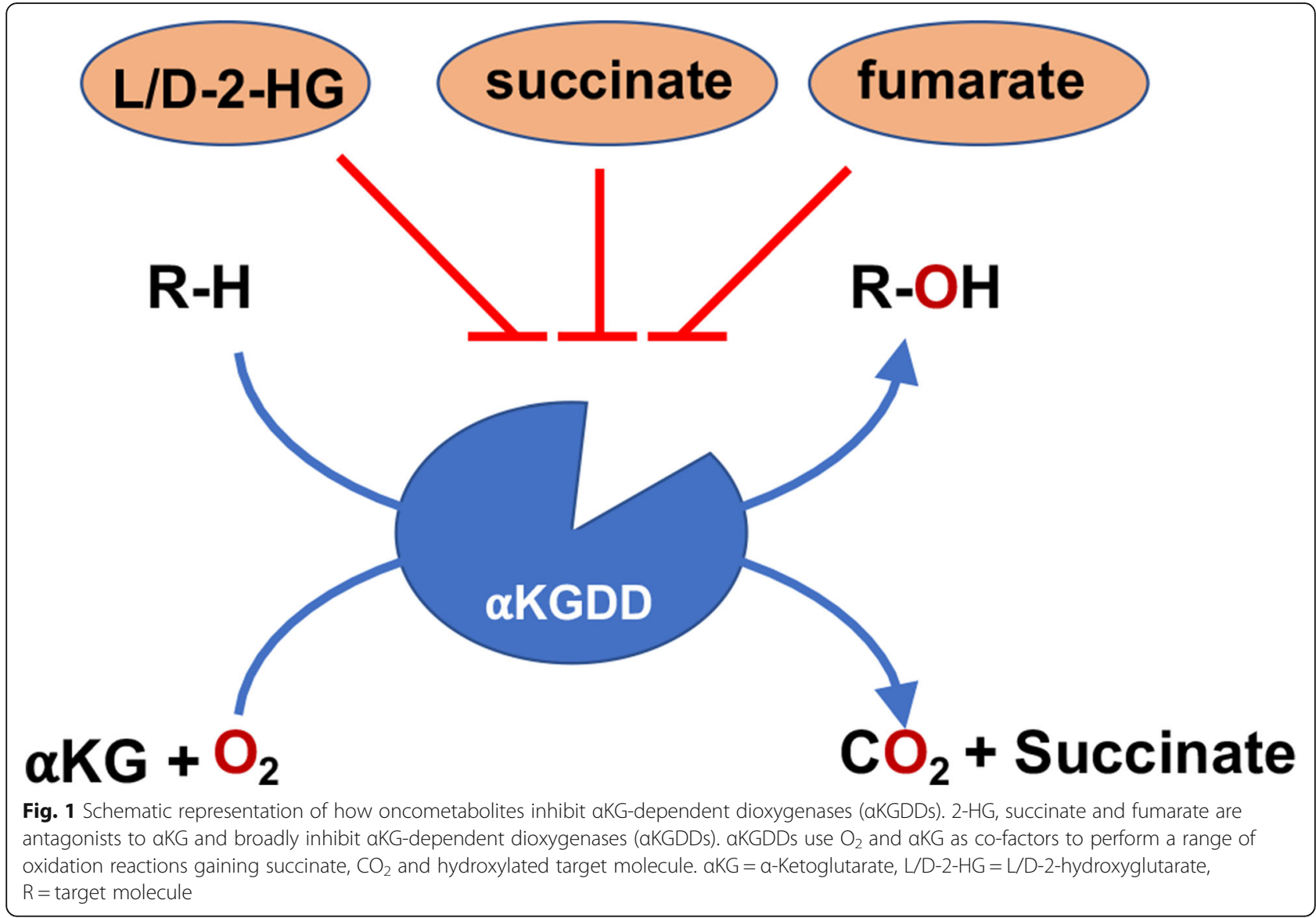

5-methylcytosines $(5 \mathrm{mCs})$ and thereby promotes DNA demethylation in normal cells [121]. Therefore, accumulation of succinate was associated with inhibition of TETs resulting in a decrease of $5 \mathrm{mC}$ oxidation and DNA hypermethylation $[121,122]$. In line with these observations, SDH-mutated gastrointestinal tumor samples revealed a histone hypermethylation, presumably as a consequence of KDM inhibition [123]. We speculate that inhibition of KDMs by succinate accumulation may result in HRR suppression as described for 2-HGaccumulation, thereby rendering cancer cells vulnerable to PARP inhibitors $[24,115,116]$ or alkylating agents (Fig. 2).

\section{Fumarate}

Similarly, fumarate accumulation in FH mutated cells, induced epigenetic regulation of DNA/histone demethylases, with related downstream effect of cancer cells [94, 122, 124]. Interestingly, recent studies suggest a translocation of $\mathrm{FH}$ into the nucleus upon DNA damage: nuclear FH led to local production of fumarate that caused inhibition of histone H3K36 demethylation; since histone H3K36 demethylation is an important step in DDR, as it promotes binding of NHEJ proteins and thereby facilitates DNA repair, nuclear FH impaired DSB repair [125]. Furthermore, FH loss-of-function mutation conferred resistance to DNA damage upon IR and promoted early mitotic entry after IR by suppressing checkpoint maintenance [126]. We assume that fumarate accumulation in $\mathrm{FH}$-deficient cells might also inhibit HRR by acting on KDMs, leading to increased endogenous DNA damage and over-sensitivity to PARPinhibitors [116] or alkylating agents (Fig. 2).

\section{2-HG}

Generally, high cellular 2-HG levels have been associated with malignant progression and sensitivity to RT $[16,127]$, presumably through inhibition of aKGDDs. Cancer cells with mutant IDH and accompanied 2-HG accumulation are characterized by increased sensitivity to DNAdamaging treatments, e.g. IR or alkylating agents [102, 114]. Importantly, elegant recent work revealed that 2-HG accumulation induced a defect in HRR reminiscent of BRCA1/ 2-deficient tumors as it made the respective cells vulnerable to PARP-inhibitors; interestingly the authors were able to link this effect to inhibition of $\alpha \mathrm{KG}$-dependent dioxygenases of the lysine demethylase family, KDM4A and KDM4B, and thus to epigenetic regulation of DSB repair $[16,113,128,129]$. In line with this observations, recent 


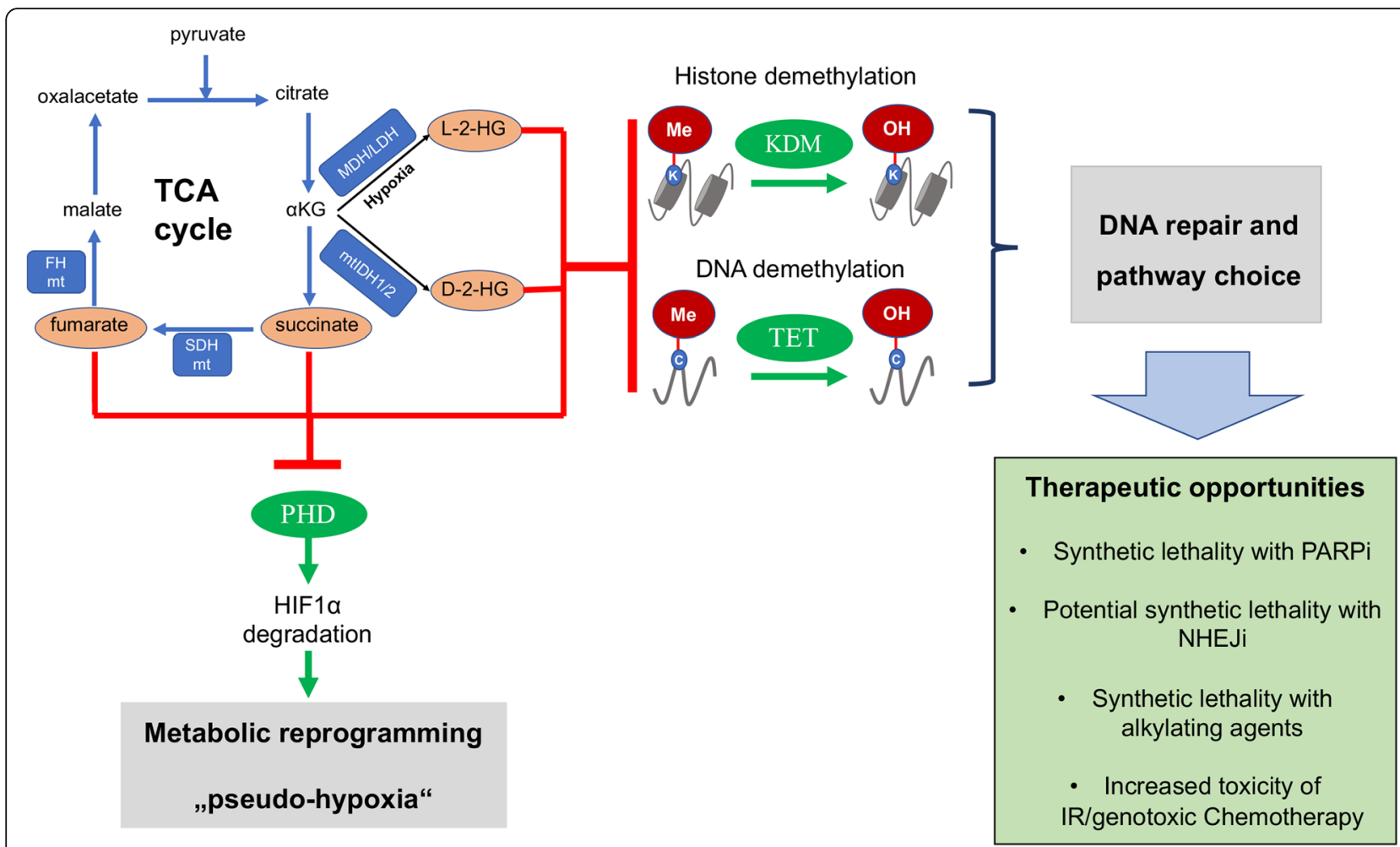

Fig. 2 Schematic representation of how oncometabolites can modulate radiosensitivity. The indicated oncometabolites (orange) can accumulate as a consequence of mutations of TCA cycle enzymes or environmental cues, such as hypoxia and even without oncogenic mutations e.g. by pharmacologic inhibition of SLC25A1. 2-HG, succinate and fumarate induce metabolic reprogramming and a "pseudo-hypoxic phenotype" via stabilisation of HIF1a. Moreover, indicated oncometabolites are competitive inhibitors of the aKG-dependent KDM and TET families of epigenetic enzymes, thereby modulating DNA repair and pathway choice and offer novel therapeutic opportunities with IR. aKG $=a-K e t o g l u t a r a t e, ~ C=$ cytosine, $\mathrm{K}=$ Lysin, L/D-2-HG = L/D-2-hydroxyglutarate, $\mathrm{mt}=$ mutant, Orange colour represents increased metabolite levels

studies further associated the function of KDMs to regulation of HRR and radioresistance of lung cancer patients $[24,115,130]$. Moreover, a recently published study by Sulkowski and coworkers has dissected some mechanistic aspects of the link between 2-HG and DSB repair on the level of KDM4B mediated H3K9me3 histone 3 lysine 9 trimethylation (H3K9me3) near DNA breaks [129]. In more detail, 2-HG mediated KDM4B inhibition resulted in an increase of $\mathrm{H} 3 \mathrm{~K} 9 \mathrm{me} 3$ at loci surrounding DNA breaks. The alteration of the histone marks interfered with proper recruitment of TIP60 and ATM, thereby reducing end resection and impairing downstream DNA repair [129]. This study emphasizes the pivotal role of 2-HG-mediated suppression of HRR and provides an excellent explanation for the relationship between oncometabolites, the DNA damage response and DSB repair [129]. However, 2-HG accumulation also inhibited alkylation repair homolog (ALKBH) DNA repair enzymes leading to enhanced sensitivity to alkylating agents $[114,115]$.

Taken together, the inhibitory effects of oncometabolites in the process of DSB repair represents a tumorspecific vulnerability offering opportunities for a tumorspecific radiosensitization (Fig. 2).

\section{Tumor hypoxia and context-dependent vulnerabilities}

Exposure to hypoxia leads to a pronounced metabolic adaptation, e.g. inhibition of the TCA cycle and oxidative phosphorylation (OXPHOS) as well as up-regulation of glycolysis, respectively [100, 131]. Activation of glycolysis under conditions of $\mathrm{O}_{2}$-deprivation is mostly regulated by activation of the hypoxia-inducible factor 1 (HIF-1) which induces broad metabolic reprogramming to balance $\mathrm{O}_{2}$ demand and provision [131, 132]. Elegant work has revealed the various roles of HIF1 in radioresistance [5, 19, 61]. Of note, overproduction of the oncometabolites 2-HG, succinate or fumarate induced a pseudo-hypoxic phenotype by HIF1 $\alpha$-stabilization under normoxic conditions [121, 122] through inhibition of $\alpha$ KGDD prolyl hydroxylases (PHD) responsible for hydroxylation and subsequent degradation of HIF1 $\alpha$ [24, 115, 130]. Thus, oncometabolite-induced HIF1 $\alpha$-mediated metabolic reprogramming towards a pseudo-hypoxic phenotype might be associated with increased resistance to certain cancer therapies, but offer potential vulnerabilities associated with the resulting DNA repair defects. As an example, inhibition of mitochondrial citrate carrier SLC25A1 induced the accumulation of 2-HG in cancer cells and this was associated with impaired repair 
of radiation-induced DNA damage [25]. Metabolic reprogramming of cancer cells exposed to acute or chronic cycling severe hypoxia with intermittent reoxygenation supported RT resistance by increasing cellular antioxidant capacity and up-regulation of the mitochondrial citrate carrier protein SLC25A1 and the dicarboxylate carrier protein SLC25A10 [10, 25, 29]. It is tempting to speculate that pharmacologic induction of oncometabolite accumulation might by a suitable strategy to induce epigenetic tuning of DNA repair pathways during therapy to enhance the efficacy of RT.

\section{Conclusions and outlook}

Exciting recent observations highlight a role of oncometabolites in the regulation of antioxidant capacity, mitochondrial respiration, and DSB repair with impact on cancer cell sensitivity to genotoxic chemotherapy and RT. For instance, TCA-cycle derived oncometaboliteaccumulation competitively suppressed the function of $\alpha K G D D s$ with relevance to epigenetic regulation of DNA repair, e.g. KDMs and TETs, resulting in DNA/ Histone hypermethylation. However, the biochemical binding properties of the different oncometabolites suggest different flavors of specificity for $\alpha$ KGDDs with relevance to DNA repair [121, 133]. While fumarateaccumulation promotes protein succination and thereby triggers a plethora of biological changes that may synergise with or counteract $\alpha$ KGDD inhibition, 2-HGaccumulation suppresses the function of KDMs affecting HRR [16, 61, 129]. Furthermore, fumarate and 2-HG evoke opposite effects on mTOR signaling, with consequences for the development of certain tumor types $[134,135]$ and potential indirect influence on radiation sensitivity. Additional studies suggest that specific environmental or nutritional circumstances may even promote oncometabolite-accumulation in the absence of the underpinning oncogenic mutations. This might be relevant for the reported link between oncometabolite and cancer stemness or suppression of the anti-tumor immune response thereby shaping the tumor immune microenvironment as suggested by others. Furthermore, RT-induced changes in miRNA-expression might mediate therapy-induced oncometabolite accumulation and tumor repopulation [71]. Finally, other oncometabolites such as Sarcosine, a N-methyl derivative of the amino acid glycine observed in prostate cancer, also increase DNA methylation, yet their impact on DNA repair and radiosensitivity remains to be determined. Taken together, a better mechanistic understanding of the accumulation of oncometabolites, the metabolic communication between mitochondria and the nucleus, and of the metabolic regulation of epigenetic enzymes with impact on DNA repair will allow to use genetic defects and the altered interplay between cell metabolism, epigenetic enzymes and DNA repair for tumor-specific synthetic lethality in combination with DNA repair inhibitors tumor-specific radiosensitization, or both in the future. The identification of biochemical nodes for oncometabolite induction may even allow us to use metabolic inhibitors, such as mitochondrial transporters, for temporal induction of oncometabolites during radiotherapy in tumors without genetic oncometabolite-induction. We assume that combining systematic cell biology and radiobiology investigations with mathematical modeling of the obtained results will allow to identify critical epigenetic regulators of radiosensitivity and the discovery of metabolic targets for tumor-specific radiosensitization.

\section{Methods}

Studies were identified via searching electronic databases e.g. Pubmed, Web of Science with key words: radiotherapy, ionizing radiation, radiation therapy, DNA damage response, DDR, DNA repair, epigenetic regulation, epigenetic modulation, double-strand break, DSB, oncometabolite, 2-hydroxyglutarate, 2-HG, fumarate and succinate for publications in English. Studies and reviews related with ionizing radiation and/or metabolism were included. Publications focusing on novel cancer therapies, such as hormonal therapy, were taken out of consideration. To be more reliable, conclusions from different publications had been cross examined. Unpublished materials were not included in this review.

\begin{abstract}
Abbreviations
aKGDD: a-ketoglutarate-dependent dioxygenase; 2-HG: 2-hydroxyglutarate; 5mCs: 5-methylcytosines; ADSL: adenylosuccinate lyase;

ADSL: adenylosuccinate lyase; ALKBH: Alkylation Repair Homolog; altEJ: alternative end-joining; BRCA1/2: early onset Breast cancer 1/2; DDR: DNA damage response; DNA-PK: DNA-dependent serine/threonine protein kinase; DSB: DNA double strand break; EJ: end-joining; EMT: epithelial-tomesenchymal transition; ETC: Electron transport chain; FH: fumarate hydratase; HCC: hepatocellular carcinoma; HIF: hypoxia-inducible factor; HLRC C: hereditary leiomyomatosis and renal cell cancer; HRR: homologous recombination repair; IDH: isocitrate dehydrogenase; IR: Ionizing radiation; KDM: histone lysine demethylase; LDH: lactate dehydrogenase; MDH: malate dehydrogenase; NHEJ: non-homologous end-joining; O2: molecular Oxygen; OXPHOS: oxidative phosphorylation; PARP: Poly(ADP-Ribose)-Polymerase; PHD: prolyl hydroxylase; PPP: pentose phosphate pathway; ROS: reactive oxygen species; RT: Radiotherapy; SDH: Succinate dehydrogenase; SUCN R1: succinate receptor 1; TCA: tricarboxylic acid cycle; TET: ten eleven translocation DNA demethylase; VEGF: vascular endothelial growth factor; aKG: a-Ketoglutarate
\end{abstract}

\section{Acknowledgements}

Not applicable.

\section{Authors' contributions}

K.X., V.J. and J.M performed literature research and wrote the original manuscript draft. V.J. and J.M. acquired the funding. K.X. and J.M. made the figures. All authors critically edited revised, and approved the final version of the manuscript.

\section{Funding}

The work was supported by grants of the German Research Foundation DFG GRK1739/2 to VJ, a grant for the Innovative Training Network (ITN) THERADNET (2019-2023) from the European Commission under the Framework Programme 
for Research and Innovation Horizon 2020 under the Marie Skłodowska-Curie Grant Agreement No. 860245 to VJ. and JM, the Deutsche Krebshilfe/MildredScheel-Stiftung (grant number 70112711) to VJ and the China Cooperation Office of the Medical Faculty of the University of Duisburg-Essen within the frame of a research scholarship to KX. Open access funding provided by Projekt DEAL.

\section{Availability of data and materials}

Not applicable.

\section{Ethics approval and consent to participate}

Not applicable.

\section{Consent for publication}

Not applicable.

\section{Competing interests}

The authors declare that they have no competing interests.

\section{Received: 15 May 2020 Accepted: 6 August 2020}

\section{Published online: 14 August 2020}

\section{References}

1. Kirsch DG, Diehn M, Kesarwala AH, Maity A, Morgan MA, Schwarz JK, et al. The future of radiobiology. J Natl Cancer Inst. 2018;110(4):329-40.

2. Salem A, Asselin MC, Reymen B, Jackson A, Lambin P, West CML, et al. Targeting Hypoxia to Improve Non-Small Cell Lung Cancer Outcome. J Natl Cancer Inst. 2018;110(1).

3. Barcellos-Hoff MH, Lyden D, Wang TC. The evolution of the cancer niche during multistage carcinogenesis. Nat Rev Cancer. 2013;13(7):511-8.

4. Abshire D, Lang MK. The evolution of radiation therapy in treating Cancer. Semin Oncol Nurs. 2018;34(2):151-7.

5. Bristow RG, Hill RP. Hypoxia and metabolism. Hypoxia, DNA repair and genetic instability. Nat Rev Cancer. 2008;8(3):180-92.

6. Mladenov E, Magin S, Soni A, Iliakis G. DNA double-strand break repair as determinant of cellular radiosensitivity to killing and target in radiation therapy. Front Oncol. 2013;3:113.

7. Bennett $C B$, Lewis $A L$, Baldwin $K K$, Resnick MA. Lethality induced by a single site-specific double-strand break in a dispensable yeast plasmid. Proc Natl Acad Sci. 1993;90(12):5613-7.

8. Mladenov $\mathrm{E}$, lliakis $\mathrm{G}$. Induction and repair of DNA double strand breaks: the increasing spectrum of non-homologous end joining pathways. Mutat Res. 2011;711(1-2):61-72.

9. Schipler A, lliakis G. DNA double-strand-break complexity levels and their possible contributions to the probability for error-prone processing and repair pathway choice. Nucleic Acids Res. 2013;41(16):7589-605.

10. Matschke J, Riffkin H, Klein D, Handrick R, Ludemann L, Metzen E, et al. Targeted inhibition of glutamine-dependent glutathione metabolism overcomes death resistance induced by chronic cycling hypoxia. Antioxid Redox Signal. 2016;25(2):89-107.

11. Ye LF, Chaudhary KR, Zandkarimi F, Harken AD, Kinslow CJ, Upadhyayula PS, et al. Radiation-induced lipid peroxidation triggers Ferroptosis and synergizes with Ferroptosis inducers. ACS Chem Biol. 2020;15(2):469-84.

12. Marampon F, Codenotti S, Megiorni F, Del Fattore A, Camero S, Gravina GL, et al. NRF2 orchestrates the redox regulation induced by radiation therapy, sustaining embryonal and alveolar rhabdomyosarcoma cells radioresistance. J Cancer Res Clin Oncol. 2019;145(4):881-93.

13. Lord CJ, Ashworth A. PARP inhibitors: synthetic lethality in the clinic. Science. 2017;355(6330):1152-8.

14. Ashworth A, Lord CJ. Synthetic lethal therapies for cancer: what's next after PARP inhibitors? Nat Rev Clin Oncol. 2018;15(9):564.

15. McLornan DP, List A, Mufti GJ. Applying synthetic lethality for the selective targeting of cancer. N Engl J Med. 2014;371(18):1725-35.

16. Sulkowski PL, Corso CD, Robinson ND, Scanlon SE, Purshouse KR, Bai H, et al. 2-Hydroxyglutarate produced by neomorphic IDH mutations suppresses homologous recombination and induces PARP inhibitor sensitivity. Sci Transl Med. 2017:9(375).

17. Kass EM, Moynahan ME, Jasin M. When genome maintenance Goes badly awry. Mol Cell. 2016;62(5):777-87.

18. Chan N, Koritzinsky M, Zhao H, Bindra R, Glazer PM, Powell S, et al. Chronic hypoxia decreases synthesis of homologous recombination proteins to offset chemoresistance and radioresistance. Cancer Res. 2008;68(2):605-14.
19. Scanlon SE, Glazer PM. Multifaceted control of DNA repair pathways by the hypoxic tumor microenvironment. DNA Repair (Amst). 2015;32:180-9.

20. Kaplan AR, Glazer PM. Impact of hypoxia on DNA repair and genome integrity. Mutagenesis. 2020;35(1):61-8.

21. Stadler J, Richly H. Regulation of DNA Repair Mechanisms: How the Chromatin Environment Regulates the DNA Damage Response. Int J Mol Sci. 2017;18(8).

22. Zernickel E, Sak A, Riaz A, Klein D, Groneberg M, Stuschke M. Targeting of BRM sensitizes BRG1-mutant lung Cancer cell lines to radiotherapy. Mol Cancer Ther. 2019;18(3):656-66.

23. Niedermaier B, Sak A, Zernickel E, Xu S, Groneberg M, Stuschke M. Targeting ARID1A-mutant colorectal cancer: depletion of ARID1B increases radiosensitivity and modulates DNA damage response. Sci Rep. 2019;9(1): 18207.

24. Bayo J, Tran TA, Wang L, Pena-Llopis S, Das AK, Martinez ED. Jumonji inhibitors overcome Radioresistance in Cancer through changes in H3K4 methylation at double-Strand breaks. Cell Rep. 2018;25(4):1040-50 e5.

25. Hlouschek J, Hansel C, Jendrossek V, Matschke J. The mitochondrial citrate carrier (SLC25A1) sustains redox homeostasis and mitochondrial metabolism supporting Radioresistance of Cancer cells with tolerance to cycling severe hypoxia. Front Oncol. 2018;8:170.

26. Rouschop KM, Dubois LJ, Keulers TG, van den Beucken T, Lambin P, Bussink J, et al. PERK/elF2alpha signaling protects therapy resistant hypoxic cells through induction of glutathione synthesis and protection against ROS. Proc Natl Acad Sci U S A. 2013;110(12):4622-7.

27. Nakashima R, Goto Y, Koyasu S, Kobayashi M, Morinibu A, Yoshimura M, et al. UCHL1-HIF-1 axis-mediated antioxidant property of cancer cells as a therapeutic target for radiosensitization. Sci Rep. 2017;7(1):6879.

28. Hatem E, El Banna N, Huang ME. Multifaceted roles of glutathione and glutathione-based Systems in Carcinogenesis and Anticancer Drug Resistance. Antioxid Redox Signal. 2017;27(15):1217-34

29. Houschek J, Ritter V, Wirsdorfer F, Klein D, Jendrossek V, Matschke J. Targeting SLC25A10 alleviates improved antioxidant capacity and associated radioresistance of cancer cells induced by chronic-cycling hypoxia. Cancer Lett. 2018;439:24-38

30. Matschke J, Wiebeck E, Hurst S, Rudner J, Jendrossek V. Role of SGK1 for fatty acid uptake, cell survival and radioresistance of $\mathrm{NCl}-\mathrm{H} 460$ lung cancer cells exposed to acute or chronic cycling severe hypoxia. Radiat Oncol. 2016;11:75.

31. Grasso D, Medeiros HCD, Zampieri LX, Bol V, Danhier $P$, van Gisbergen MW, et al. Fitter mitochondria are associated with Radioresistance in human head and neck SQD9 Cancer cells. Front Pharmacol. 2020;11:263.

32. Barker HE, Paget JT, Khan AA, Harrington KJ. The tumour microenvironment after radiotherapy: mechanisms of resistance and recurrence. Nat Rev Cancer. 2015:15(7):409-25.

33. Harris AL. Hypoxia--a key regulatory factor in tumour growth. Nat Rev Cancer. 2002:2(1):38-47.

34. Smits KM, Melotte V, Niessen HE, Dubois L, Oberije C, Troost EG, et al. Epigenetics in radiotherapy: where are we heading? Radiother Oncol. 2014; $111(2): 168-77$

35. Kim EH, Park AK, Dong SM, Ahn JH, Park WY. Global analysis of CpG methylation reveals epigenetic control of the radiosensitivity in lung cancer cell lines. Oncogene. 2010:29(33):4725-31.

36. de Cubas AA, Rathmell WK. Epigenetic modifiers: activities in renal cell carcinoma. Nat Rev Urol. 2018;15(10):599-614.

37. Shannan B, Matschke J, Chauvistre H, Vogel F, Klein D, Meier F, et al. Sequence-dependent cross-resistance of combined radiotherapy plus BRAF(V600E) inhibition in melanoma. Eur J Cancer. 2019;109:137-53.

38. Hayakawa T, Zhang F, Hayakawa N, Ohtani Y, Shinmyozu K, Nakayama J, et al. MRG15 binds directly to PALB2 and stimulates homology-directed repair of chromosomal breaks. J Cell Sci. 2010;123(Pt 7):1124-30.

39. Gong F, Miller KM. Histone methylation and the DNA damage response. Mutat Res. 2019;780:37-47

40. Wei S, Li C, Yin Z, Wen J, Meng H, Xue L, et al. Histone methylation in DNA repair and clinical practice: new findings during the past 5-years. J Cancer. 2018:9(12):2072-81.

41. Miousse IR, Kutanzi KR, Koturbash I. Effects of ionizing radiation on DNA methylation: from experimental biology to clinical applications. Int J Radiat Biol. 2017;93(5):457-69.

42. Lahtz C, Pfeifer GP. Epigenetic changes of DNA repair genes in cancer. J Mol Cell Biol. 2011;3(1):51-8. 
43. Dabin J, Fortuny A, Polo SE. Epigenome maintenance in response to DNA damage. Mol Cell. 2016;62(5):712-27.

44. Belotserkovskaya R, Raga Gil E, Lawrence N, Butler R, Clifford G, Wilson MD, et al. PALB2 chromatin recruitment restores homologous recombination in BRCA1-deficient cells depleted of 53BP1. Nat Commun. 2020;11(1):819.

45. Turner N, Tutt A, Ashworth A. Hallmarks of'BRCAness' in sporadic cancers. Nat Rev Cancer. 2004;4(10):814-9.

46. Pilie PG, Tang C, Mills GB, Yap TA. State-of-the-art strategies for targeting the DNA damage response in cancer. Nat Rev Clin Oncol. 2019;16(2):81-104

47. Lord CJ, Ashworth A. BRCAness revisited. Nat Rev Cancer. 2016;16(2):110-20.

48. Knijnenburg TA, Wang L, Zimmermann MT, Chambwe N, Gao GF, Cherniack $A D$, et al. Genomic and molecular landscape of DNA damage repair deficiency across the Cancer genome atlas. Cell Rep. 2018;23(1):239-54 e6.

49. Okayasu R. Repair of DNA damage induced by accelerated heavy ions--a mini review. Int J Cancer. 2012;130(5):991-1000.

50. Szymonowicz K, Krysztofiak A, Linden JV, Kern A, Deycmar S, Oeck S, et al. Proton Irradiation Increases the Necessity for Homologous Recombination Repair Along with the Indispensability of Non-Homologous End Joining. Cells. 2020;9(4).

51. Grosse N, Fontana AO, Hug EB, Lomax A, Coray A, Augsburger M, et al. Deficiency in homologous recombination renders mammalian cells more sensitive to proton versus photon irradiation. Int J Radiat Oncol Biol Phys. 2014;88(1):175-81

52. Fontana AO, Augsburger MA, Grosse N, Guckenberger M, Lomax AJ, Sartori AA, et al. Differential DNA repair pathway choice in cancer cells after proton- and photon-irradiation. Radiother Oncol. 2015;116(3):374-80.

53. Liu Q, Ghosh P, Magpayo N, Testa M, Tang S, Gheorghiu L, et al. Lung cancer cell line screen links fanconi anemia/BRCA pathway defects to increased relative biological effectiveness of proton radiation. Int J Radiat Oncol Biol Phys. 2015;91(5):1081-9.

54. Gaude E, Frezza C. Tissue-specific and convergent metabolic transformation of cancer correlates with metastatic potential and patient survival. Nat Commun. 2016;7:13041.

55. Reznik E, Wang Q, La K, Schultz N, Sander C. Mitochondrial respiratory gene expression is suppressed in many cancers. Elife. 2017;6.

56. Gaude E, Frezza C. Defects in mitochondrial metabolism and cancer. Cancer \& metabolism. 2014;2(1):1-9.

57. Ward PS, Thompson CB. Metabolic reprogramming: a cancer hallmark even Warburg did not anticipate. Cancer Cell. 2012;21(3):297-308.

58. Thompson CB. Metabolic enzymes as oncogenes or tumor suppressors. N Engl J Med. 2009;360(8):813-5.

59. Schulze A, Harris AL. How cancer metabolism is tuned for proliferation and vulnerable to disruption. Nature. 2012;491(7424):364-73.

60. Yang M, Soga T, Pollard PJ, Adam J. The emerging role of fumarate as an oncometabolite. Front Oncol. 2012;2:85.

61. Sciacovelli M, Frezza C. Oncometabolites: unconventional triggers of oncogenic signalling cascades. Free Radic Biol Med. 2016;100:175-81.

62. Zecchini V, Frezza C. Metabolic synthetic lethality in cancer therapy. Biochim Biophys Acta Bioenerg. 2017;1858(8):723-31.

63. Nota B, Struys EA, Pop A, Jansen EE, Fernandez Ojeda MR, Kanhai WA, et al. Deficiency in SLC25A1, encoding the mitochondrial citrate carrier, causes combined D-2- and L-2-hydroxyglutaric aciduria. Am J Hum Genet. 2013; 92(4):627-31.

64. Prasun P, Young S, Salomons G, Werneke A, Jiang YH, Struys E, et al. Expanding the Clinical Spectrum of Mitochondrial Citrate Carrier (SLC25A1) Deficiency: Facial Dysmorphism in Siblings with Epileptic Encephalopathy and Combined D,L-2-Hydroxyglutaric Aciduria. JIMD Rep 2015;19:111-115.

65. Oermann EK, WU J, Guan KL, Xiong Y. Alterations of metabolic genes and metabolites in cancer. Semin Cell Dev Biol. 2012;23(4):370-80.

66. Frezza C, Pollard PJ, Gottlieb E. Inborn and acquired metabolic defects in cancer. J Mol Med (Berl). 2011;89(3):213-20.

67. Kaelin WG Jr, McKnight SL. Influence of metabolism on epigenetics and disease. Cell. 2013;153(1):56-69.

68. Anso E, Weinberg SE, Diebold LP, Thompson BJ, Malinge S, Schumacker PT, et al. The mitochondrial respiratory chain is essential for haematopoietic stem cell function. Nat Cell Biol. 2017;19(6):614-25.

69. Walle T, Martinez Monge R, Cerwenka A, Ajona D, Melero I, Lecanda F. Radiation effects on antitumor immune responses: current perspectives and challenges. Ther Adv Med Oncol. 2018;10:1758834017742575.
70. Menendez JA, Corominas-Faja B, Cuyas E, Garcia MG, Fernandez-Arroyo S, Fernandez AF, et al. Oncometabolic nuclear reprogramming of Cancer Stemness. Stem Cell Reports. 2016;6(3):273-83.

71. Dando I, Pozza ED, Ambrosini G, Torrens-Mas M, Butera G, Mullappilly N, et al. Oncometabolites in cancer aggressiveness and tumour repopulation. Biol Rev Camb Philos Soc. 2019;94(4):1530-46.

72. Bunse L, Pusch S, Bunse T, Sahm F, Sanghvi K, Friedrich M, et al. Suppression of antitumor $T$ cell immunity by the oncometabolite (R)-2hydroxyglutarate. Nat Med. 2018;24(8):1192-203.

73. Zhao T, Mu X, You Q. Succinate: an initiator in tumorigenesis and progression. Oncotarget. 2017;8(32):53819.

74. Rustin P, Munnich A, Rotig A. Succinate dehydrogenase and human diseases: new insights into a well-known enzyme. Eur J Hum Genet. 2002; 10(5):289-91.

75. Yang M, Soga T, Pollard PJ. Oncometabolites: linking altered metabolism with cancer. J Clin Invest. 2013;123(9):3652-8.

76. Wojtovich AP, Foster TH. Optogenetic control of ROS production. Redox Biol. 2014;2:368-76.

77. Van Vranken JG, Na U, Winge DR, Rutter J. Protein-mediated assembly of succinate dehydrogenase and its cofactors. Crit Rev Biochem Mol Biol. 2015; 50(2):168-80.

78. Hogberg C, Gidlof O, Tan C, Svensson S, Nilsson-Ohman J, Erlinge D, et al. Succinate independently stimulates full platelet activation via CAMP and phosphoinositide 3-kinase-beta signaling. J Thromb Haemost. 2011;9(2):361-72.

79. He W, Miao FJ-P, Lin DC-H, Schwandner RT, Wang Z, Gao J, et al. Citric acid cycle intermediates as ligands for orphan G-protein-coupled receptors. Nature. 2004;429(6988):188-93.

80. Aspuria P-JP, Lunt SY, Väremo L, Vergnes L, Gozo M, Beach JA, et al. Succinate dehydrogenase inhibition leads to epithelial-mesenchymal transition and reprogrammed carbon metabolism. Cancer \& metabolism. 2014:2(1):1-15.

81. Loriot C, Domingues M, Berger A, Menara M, Ruel M, Morin A, et al. Deciphering the molecular basis of invasiveness in Sdhb-deficient cells. Oncotarget. 2015;6(32):32955.

82. Park SY, Le CT, Sung KY, Choi DH, Cho EH. Succinate induces hepatic fibrogenesis by promoting activation, proliferation, and migration, and inhibiting apoptosis of hepatic stellate cells. Biochem Biophys Res Commun. 2018;496(2):673-8

83. Ko SH, Choi GE, Oh JY, Lee HJ, Kim JS, Chae CW, et al. Succinate promotes stem cell migration through the GPR91-dependent regulation of DRP1mediated mitochondrial fission. Sci Rep. 2017;7(1):12582.

84. Tseng PL, Wu WH, Hu TH, Chen CW, Cheng HC, Li CF, et al. Decreased succinate dehydrogenase $B$ in human hepatocellular carcinoma accelerates tumor malignancy by inducing the Warburg effect. Sci Rep. 2018;8(1):3081.

85. Weber A, Klocker H, Oberacher H, Gnaiger E, Neuwirt H, Sampson N, et al. Succinate Accumulation Is Associated with a Shift of Mitochondrial Respiratory Control and HIF-1alpha Upregulation in PTEN Negative Prostate Cancer Cells. Int J Mol Sci. 2018;19(7).

86. Tannahill GM, Curtis AM, Adamik J, Palsson-McDermott EM, McGettrick AF, Goel $\mathrm{G}$, et al. Succinate is an inflammatory signal that induces IL-1 beta through HIF-1alpha. Nature. 2013;496(7444):238-42.

87. Al-Mayah AH, Irons SL, Pink RC, Carter DR, Kadhim MA. Possible role of exosomes containing RNA in mediating nontargeted effect of ionizing radiation. Radiat Res. 2012;177(5):539-45.

88. Bastos N, Ruivo CF, da Silva S, Melo SA. Exosomes in cancer: use them or target them? Semin Cell Dev Biol. 2018;78:13-21.

89. Rupaimoole R, Calin GA, Lopez-Berestein G, Sood AK. miRNA deregulation in Cancer cells and the tumor microenvironment. Cancer Discov. 2016;6(3): 235-46.

90. Puissegur MP, Mazure NM, Bertero T, Pradelli L, Grosso S, Robbe-Sermesant $\mathrm{K}$, et al. miR-210 is overexpressed in late stages of lung cancer and mediates mitochondrial alterations associated with modulation of HIF-1 activity. Cell Death Differ. 2011;18(3):465-78.

91. Mu X, Zhao T, Xu C, Shi W, Geng B, Shen J, et al. Oncometabolite succinate promotes angiogenesis by upregulating VEGF expression through GPR91mediated STAT3 and ERK activation. Oncotarget. 2017;8(8):13174.

92. Tyrakis PA, Yurkovich ME, Sciacovelli M, Papachristou EK, Bridges HR, Gaude E, et al. Fumarate Hydratase loss causes combined respiratory chain defects. Cell Rep. 2017;21(4):1036-47. 
93. Schmidt C, Sciacovelli M, Frezza C, editors. Fumarate hydratase in cancer: A multifaceted tumour suppressor. Seminars in cell \& developmental biology; 2020: Elsevier.

94. Isaacs JS, Jung YJ, Mole DR, Lee S, Torres-Cabala C, Chung YL, et al. HIF overexpression correlates with biallelic loss of fumarate hydratase in renal cancer: novel role of fumarate in regulation of HIF stability. Cancer Cell. 2005;8(2):143-53.

95. Suo $G$, Jiang $Y$, Cowan B, Wang JY. Platelet-derived growth factor $C$ is upregulated in human uterine fibroids and regulates uterine smooth muscle cell growth. Biol Reprod. 2009;81(4):749-58.

96. Yang Y, Lane AN, Ricketts CJ, Sourbier C, Wei MH, Shuch B, et al. Metabolic reprogramming for producing energy and reducing power in fumarate hydratase null cells from hereditary leiomyomatosis renal cell carcinoma. PLoS One. 2013;8(8):e72179.

97. King A, Selak MA, Gottlieb E. Succinate dehydrogenase and fumarate hydratase: linking mitochondrial dysfunction and cancer. Oncogene. 2006; 25(34):4675-82.

98. Eichner LJ, Perry MC, Dufour CR, Bertos N, Park M, St-Pierre J, et al. miR-378( *) mediates metabolic shift in breast cancer cells via the PGC-1beta/ ERRgamma transcriptional pathway. Cell Metab. 2010;12(4):352-61.

99. Intlekofer AM, Dematteo RG, Venneti S, Finley LW, Lu C, Judkins AR, et al. Hypoxia induces production of L-2-Hydroxyglutarate. Cell Metab. 2015;22(2): 304-11.

100. Oldham WM, Clish CB, Yang Y, Loscalzo J. Hypoxia-mediated increases in L2-hydroxyglutarate coordinate the metabolic response to reductive stress. Cell Metab. 2015;22(2):291-303.

101. Intlekofer AM, Wang B, Liu H, Shah H, Carmona-Fontaine C, Rustenburg AS, et al. L-2-Hydroxyglutarate production arises from noncanonical enzyme function at acidic pH. Nat Chem Biol. 2017;13(5):494-500.

102. Dang L, White DW, Gross S, Bennett BD, Bittinger MA, Driggers EM, et al. Cancer-associated IDH1 mutations produce 2-hydroxyglutarate. Nature. 2009;462(7274):739-44

103. Losman JA, Kaelin WG Jr. What a difference a hydroxyl makes: mutant IDH, (R)-2-hydroxyglutarate, and cancer. Genes Dev. 2013;27(8):836-52.

104. Andronesi OC, Loebel F, Bogner W, Marjanska M, Vander Heiden MG, lafrate $\mathrm{AJ}$, et al. Treatment response assessment in IDH-mutant Glioma patients by noninvasive 3D functional spectroscopic mapping of 2-Hydroxyglutarate. Clin Cancer Res. 2016;22(7):1632-41.

105. Mullen AR, Hu Z, Shi X, Jiang L, Boroughs LK, Kovacs Z, et al. Oxidation of alpha-ketoglutarate is required for reductive carboxylation in cancer cells with mitochondrial defects. Cell Rep. 2014;7(5):1679-90.

106. Reinecke CJ, Koekemoer G, van der Westhuizen FH, Louw R, Lindeque JZ, Mienie $L$, et al. Metabolomics of urinary organic acids in respiratory chain deficiencies in children. Metabolomics. 2011;8(2):264-83.

107. Worth AJ, Gillespie KP, Mesaros C, Guo L, Basu SS, Snyder NW, et al. Rotenone Stereospecifically increases (S)-2-Hydroxyglutarate in SH-SY5Y neuronal cells. Chem Res Toxicol. 2015;28(5):948-54.

108. Liu X, Zhang Y, Ni M, Cao H, Signer RA, Li D, et al. Regulation of mitochondrial biogenesis in erythropoiesis by mTORC1-mediated protein translation. Nat Cell Biol. 2017;19(6):626-38.

109. Menendez JA. Metabolic control of cancer cell stemness: lessons from iPS cells. Cell Cycle. 2015;14(24):3801-11.

110. Corrado M, Scorrano L, Campello S. Changing perspective on oncometabolites: from metabolic signature of cancer to tumorigenic and immunosuppressive agents. Oncotarget. 2016;7(29):46692-706.

111. Kolukula VK, Sahu G, Wellstein A, Rodriguez OC, Preet A, lacobazzi V, et al. SLC25A1, or CIC, is a novel transcriptional target of mutant p53 and a negative tumor prognostic marker. Oncotarget. 2014;5(5):1212.

112. Shaik S, Munro AW, Sen S, Mowat C, Nam W, Derat E, et al. Iron-containing enzymes: versatile catalysts of hydroxylation reactions in nature: Royal Society of Chemistry; 2011.

113. Gagné LM, Boulay K, Topisirovic I, Huot M-É, Mallette FA. Oncogenic activities of IDH1/2 mutations: from epigenetics to cellular signaling. Trends Cell Biol. 2017;27(10):738-52.

114. Wang P, Wu J, Ma S, Zhang L, Yao J, Hoadley KA, et al. Oncometabolite D-2Hydroxyglutarate inhibits ALKBH DNA repair enzymes and sensitizes IDH mutant cells to alkylating agents. Cell Rep. 2015;13(11):2353-61.

115. Young LC, McDonald DW, Hendzel MJ. Kdm4b histone demethylase is a DNA damage response protein and confers a survival advantage following gamma-irradiation. J Biol Chem. 2013;288(29):21376-88.
116. Sulkowski PL, Sundaram RK, Oeck S, Corso CD, Liu Y, Noorbakhsh S, et al. Krebs-cycle-deficient hereditary cancer syndromes are defined by defects in homologous-recombination DNA repair. Nat Genet. 2018;50(8):1086-92.

117. Xu W, Yang H, Liu Y, Yang Y, Wang P, Kim SH, et al. Oncometabolite 2hydroxyglutarate is a competitive inhibitor of alpha-ketoglutaratedependent dioxygenases. Cancer Cell. 2011;19(1):17-30.

118. Turcan S, Makarov V, Taranda J, Wang Y, Fabius AWM, Wu W, et al. MutantIDH1-dependent chromatin state reprogramming, reversibility, and persistence. Nat Genet. 2018;50(1):62-72.

119. Harrington $K$, Jankowska $P$, Hingorani M. Molecular biology for the radiation oncologist: the 5 Rs of radiobiology meet the hallmarks of cancer. Clin Oncol (R Coll Radiol). 2007;19(8):561-71.

120. Tang $L$, Wei $F$, Wu $Y$, He $Y$, Shi $L$, Xiong $F$, et al. Role of metabolism in cancer cell radioresistance and radiosensitization methods. J Exp Clin Cancer Res. 2018;37(1):87.

121. Xiao M, Yang H, Xu W, Ma S, Lin H, Zhu H, et al. Inhibition of alpha-KGdependent histone and DNA demethylases by fumarate and succinate that are accumulated in mutations of $\mathrm{FH}$ and $\mathrm{SDH}$ tumor suppressors. Genes Dev. 2012;26(12):1326-38.

122. Rasmussen KD, Helin K. Role of TET enzymes in DNA methylation, development, and cancer. Genes Dev. 2016;30(7):733-50.

123. Killian JK, Kim SY, Miettinen M, Smith C, Merino M, Tsokos M, et al. Succinate dehydrogenase mutation underlies global epigenomic divergence in gastrointestinal stromal tumor. Cancer Discov. 2013;3(6):648-57.

124. Park SY, Park JW, Chun YS. Jumonji histone demethylases as emerging therapeutic targets. Pharmacol Res. 2016;105:146-51.

125. Jiang Y, Qian X, Shen J, Wang Y, Li X, Liu R, et al. Local generation of fumarate promotes DNA repair through inhibition of histone $\mathrm{H3}$ demethylation. Nat Cell Biol. 2015;17(9):1158-68.

126. Johnson TI, Costa ASH, Ferguson AN, Frezza C. Fumarate hydratase loss promotes mitotic entry in the presence of DNA damage after ionising radiation. Cell Death \& Disease. 2018;9(9).

127. Molenaar RJ, Maciejewski JP, Wilmink JW, van Noorden CJF. Wild-type and mutated IDH1/2 enzymes and therapy responses. Oncogene. 2018;37(15): 1949-60.

128. Chen F, Bian K, Tang Q, Fedeles BI, Singh V, Humulock ZT, et al. Oncometabolites d-and I-2-hydroxyglutarate inhibit the AlkB family DNA repair enzymes under physiological conditions. Chem Res Toxicol. 2017; 30(4):1102-10.

129. Sulkowski PL, Oeck S, Dow J, Economos NG, Mirfakhraie L, Liu Y, et al. Oncometabolites suppress DNA repair by disrupting local chromatin signalling. Nature. 2020;582(7813):586-91.

130. Kuo KT, Huang WC, Bamodu OA, Lee WH, Wang CH, Hsiao M, et al. Histone demethylase JARID1B/KDM5B promotes aggressiveness of non-small cell lung cancer and serves as a good prognostic predictor. Clin Epigenetics. 2018;10(1):107.

131. Chiche J, Brahimi-Horn MC, Pouyssegur J. Tumour hypoxia induces a metabolic shift causing acidosis: a common feature in cancer. J Cell Mol Med. 2010;14(4):771-94.

132. Semenza GL. HIF-1 mediates metabolic responses to intratumoral hypoxia and oncogenic mutations. J Clin Invest. 2013;123(9):3664-71.

133. Laukka T, Mariani CJ, Ihantola T, Cao JZ, Hokkanen J, Kaelin WG Jr, et al. Fumarate and succinate regulate expression of hypoxia-inducible genes via TET enzymes. J Biol Chem. 2016;291(8):4256-65.

134. Sourbier C, Ricketts CJ, Matsumoto S, Crooks DR, Liao PJ, Mannes PZ, et al. Targeting ABL1-mediated oxidative stress adaptation in fumarate hydratasedeficient cancer. Cancer Cell. 2014:26(6):840-50.

135. Fu X, Chin RM, Vergnes L, Hwang H, Deng G, Xing Y, et al. 2Hydroxyglutarate inhibits ATP synthase and mTOR Signaling. Cell Metab. 2015;22(3):508-15.

\section{Publisher's Note}

Springer Nature remains neutral with regard to jurisdictional claims in published maps and institutional affiliations. 